J. Lake Sci.(湖泊科学), 2009, 21(4): 445-455

http://www.jlakes.org. E-mail: jlakes@niglas.ac.cn

(C2009 by Journal of Lake Sciences

\title{
太湖生态与环境若干问题的研究进展及其展望*
}

\author{
秦伯强 \\ (中国科学院南京地理与湖泊研究所，南京 210008)
}

摘 要: 本文着重就太湖水动力及其生态环境效应、太湖沉积物及其内源污染问题和太湖生态系统结构与功能及其蓝藻水华 等热点问题近十年来的研究进展进行了回顾. 在水动力及其生态环境效应方面, 初步摸索出一套适合太湖这样大型浅水湖泊 的研究方法, 即通过沉积物悬浮过程的研究, 把风浪与水体光照透明度、内源释放、水土界面的氧化还原环境等过程和要素 联系起来. 获得了太湖理化要素随深度变化的内部结构特征, 确立了三维水动力模拟模型在太湖应用中的必要性. 建立了太 湖光照和透明度与悬浮物的关系, 及基于悬浮物浓度的太湖初级生产力计算模型. 在太湖沉积物与内源污染问题上, 初步弄 清了太湖沉积物分布与污染物质分布的特征, 太湖沉积物悬浮的动力作用的来源与大小. 太湖水动力对内源释放的影响, 进 一步提出了适于太湖内源污染控制的判断方法. 对于太湖生态系统结构与功能及其蓝藻水华问题, 在蓝藻水华爆发过程假设 的基础上，进一步通过营养盐阈值、休眠孢子复苏等方面对此进行了完善. 研究还发现了富营养化导致生态系统退化, 生物趋 于小型化且多样性下降的现象, 营养盐循环速率加快, 加重水体富营养化程度. 进一步通过附着生物的研究, 揭示了富营养 化导致草型生态系统向藻型生态系统转化的原因. 在此基础上, 提出了生态恢复应该首先降低营养盐负荷、其次才是生态恢 复的新观念, 以及湖泊治理必须先控源截污、后生态恢复的新思路. 最后, 就这几个方面的进一步发展做出了展望.

关键词: 太湖; 水动力; 沉积物与内源污染; 生态系统结构与功能; 蓝藻水华

\section{Progress and prospect on the eco-environmental research of Lake Taihu}

\section{QIN Boqiang}

(Nanjing Institute of Geograhpy and Limnology, Chinese Academy of Sciences, Nanjing 210008, P.R.China)

Abstract: This paper reviews three hot topics associated with Lake Taihu environmental and ecological researches in the recent ten years, i.e. hydrodynamics and its effects on the lake environment and ecosystem, lake sediment and internal pollution loadings, lake ecological structure and functions related to algal bloom. In the aspect of hydrodynamics and its effects, a field approach to investigate the relationships between hydrodynamic parameters and environmental factors was developed. We found hydrodynamical intensity quantitatively related to sediment erosion and suspension, and further related to the transparency, internal loading and oxidation-deoxidization conditions at water-sediment interface. The internal structure of hydrodynamics in Lake Taihu has been achieved, so that the necessity of three dimensional hydrodynamic model has been built instead of two-dimensional hydrodynamic model for this large shallow lake. Relation functions of light penetration and intensity distribution as well as transparency related to seston have been established. Primary production estimate model of Lake Taihu based on the seston has been developed. In aspect of sediment and internal loading, the distributions of sediment and the pollutant in sediment have been clearly revealed. The main force which makes sediment resuspension was identified. The effects of hydrodynamics on the sediment resuspension and further on the nutrient releasing were investigated. A conceptual mode of nutrient releasing for large shallow lake was proposed and the criteria for internal loading control were put forward. In aspect of lake ecosystem and algal bloom, based the hypothesis of algal bloom formation, the understanding of algal bloom formation has been improved via the findings of nutrient thresholds and restoration of

* 国家自然科学基金重点项目(40730529)、国家杰出青年基金(40825004)、中国科学院重要方向性项目(KZCX2-YW-419)和 中国科学院重大交叉项目(KZCX1-YW-14)联合资助. 2008-12-31 收稿; 2009-02-17 收修改稿. 秦伯强, 男, 1963 年生, 博 士, 研究员; E-mail: qinbq@niglas.ac.cn. 
dormancy algal spores. Investigations also revealed the phenomena that eutrophication leads to degradation of ecosystem and biota tends to small sizes. The nutrient cycling will speed up and more available nutrient will be imported which in turn enhances the eutrophicating. After investigation of periphyte effects on the submerged macrophyte, the mechanism on macrophyte disappearance was clarified. Based on these findings, new idea on eutrophic lake control and ecosystem restoration was proposed, i.e. reducing the nutrient loading firstly and restoring ecosystem secondarily. Finally, the paper made perspective for the future development of these aspects.

Keywords: Lake Taihu; hydrodynamics; sediment and internal loading; ecosystem structure and function; algal bloom

十年前, 我曾经写过一篇“太湖水环境存在的主要问题、研究动态及初步进展, "[1], 发表在《湖泊科学》 1998 年第 10 卷第 4 期上. 到如今正好又是一个 10 年. 在这十年间, 太湖的水环境问题不但没有好转, 反 而其污染和富营养化问题愈演愈烈, 直至 2007 年 5 月 29 日, 发生了震惊中外的无锡太湖蓝藻危机事件 ${ }^{[2]}$. 太湖的生态环境问题成为举世瞩目的问题 ${ }^{[3]}$. 从 1998 年到今, 国家在太湖治理中投人了大量的人力物力 和措施，包括 1998 年的达标排放 ${ }^{[4]}$, “十五”期间国家“ 863 ”重大水专项 ${ }^{[5]}$, 以及最近太湖的控源截污工作. 太湖的污染和富营养化治理经历了一条曲折而充满争议的过程. 至今, 太湖水质仍然是劣 $\mathrm{V}$ 类(主要是氮 超标)为主, 蓝藻水华依然在夏季时频频出现. 所有这一切, 都只能说明我们对于太湖生态环境演化的机 理了解非常不够. 正是由于基础研究的严重不足, 难以对湖泊污染和富营养化治理实践提供有力的理论 支撑, 使得我国的湖泊治理走了不少弯路. 太湖的污染和富营养化是 1990 年代开始趋于严重的. 在这之 前, 我们在太湖所做的主要工作是湖泊资源的开发利用, 特别是水产养殖和水体农业方面 ${ }^{[6]}$. 真正围绕 太湖的富营养化机理进行研究始自本世纪初前后, 屈指算来也不过十来年. 而我们所面对却是湖沼学上 非常复杂的大型浅水湖泊. 这类湖泊, 在传统的湖沼学教科书中都鲜有描述 ${ }^{[7-8]}$. 原因是其生态环境演变 机制过于复杂而知之甚少. 复杂的原因正是“水浅”. “水浅”使得水体受上边界(水-气界面)和下边界(水土界面)影响极大, 也可以说是边壁效应很大, 这对水体生态系统有深刻而复杂的影响. 由上边界驱动的 风浪导致下边界的沉积物不断悬浮, 影响到营养盐的释放和内源负荷的大小; 进一步还影响水-土界面 的氧化还原环境, 使得对有机物降解和矿化作用甚大的微生物不断发生变化, 使得其降解的最终产物也 在不断变化; 沉积物悬浮也影响到水体光照和透明度, 并进一步表现在光合作用和初级生产力, 水生植 物分布等一系列生态效应上. 这些是浅水湖泊生态与环境系统复杂的原因所在.

但是, 不可否认这十年, 也是太湖生态环境研究取得实质性进展的时期. 在国家科技部、江苏省、中 国科学院和国家自然科学基金委员会等有关部门的支持下，围绕太湖水环境演化和富营养化机理进行了 广泛的研究. 形成了许多新的认识和成果, 使得我们对太湖富营养化问题的认识极大地得到了深化. 2005 年还在南京成功地召开了以太湖富营养化为重点的大型浅水湖泊富营养化问题的国际研讨会, 又分 别在《中国科学》(D 辑)和 Hydrobiologia 杂志上出版了专辑 ${ }^{[9-11]}$, 较系统地论述了大型浅水湖泊富营养化 的过程与机理, 有效促进了相关学科的发展, 初步明确了太湖这样大型湖泊富营养化治理的战略思路. 这对于发展具有我国特色的浅水湖泊湖沼学无疑具有非常重要的理论意义和实践价值. 本文正是出于这 样的考虑, 对太湖过去十年间有关湖泊水动力及其生态环境效应, 湖泊沉积物及其内源污染和湖泊生态 系统演化及其蓝藻水华等热点问题的研究作一回顾, 并对今后的发展作出展望. 需要说明的是, 在太湖 的生态环境研究方面，还有许多其他方面的成果，限于篇幅，没有包括在本文中. 文章所引用的文献，也 只限于本人接触到的材料, 难免挂一漏万, 敬请凉解.

\section{1 太湖的水动力过程及其生态环境效应}

由欧美科学家主导的传统的湖沼学实质上是淡水生物学或生态学. 主要的研究对象是小型湖泊或深 水湖泊 ${ }^{[7]}$. 对于物理过程、沉积物环境等对湖泊生态系统有巨大影响的大型浅水水体较少涉及. 这也是传 统湖沼学的一大不足. 当北美五大湖出现问题时, 传统的湖沼学方法和理论就无法应用. 这也是国际上 现在开始重视大湖生态环境研究的原因, 如伊利湖(Lake Erie)国际野外研究计划 ${ }^{[11]}$ 等. 而大湖与小型水 体的本质的区别就是，前者具有复杂水动力过程的影响而后者没有. 
太湖(面积 $2425 \mathrm{~km}^{2}$, 平均水深 $2.1 \mathrm{~m}$ ) 就是典型的大型浅水湖泊. 水动力在太湖生态环境演变中, 扮演 着非常重要的作用. 就我们的工作基础和研究积累而言, 从湖泊物理环境人手都是必然的选择. 在这方 面, 过去十年间的最重要成果是建立了水动力与生态环境之间联系较系统的研究方法. 该研究方法进一 步揭示风浪与沉积物悬浮之间的关系 ${ }^{[13]}$. 通过 2002 年 7 月在太湖梅梁湾中心水域一次风浪过程观察, 在 测定风速、波浪和湖流等情况下, 利用公式确定了波浪与湖流产生的作用于水-沉积物界面上的剪切力. 结果意外地发现，在许多情况下，波浪产生的剪切力要远高于湖流产生的剪切力. 风浪越大，其波浪产 生的剪切力越强. 这完全改变了以往所认为的湖流是主要水动力过程的概念. 由此可以看出, 沉积物悬 浮的动力主要来自波浪而非湖流 ${ }^{[13-14]}$. 这个工作使得我们得以认识到, 在太湖这样的大型浅水湖泊中, 风浪对生态环境的影响远较湖流重要.

2003 年 7 月, 在太湖乌龟山附近架设 SonTek ADCP 测流仪, 开展湖流垂直结构的观察. 结果发现, 即使太湖这样水深不足 $3 \mathrm{~m}$ 的浅水湖泊，也存在湖流分层的现象(图 1). 而且，连续几天，都可以观察到表 层湖流与底层湖流存在切变的现象 (罗敳苾, 未发表的数据). 这个发现, 完全改变了我们以往认为浅水湖 泊是上下理化性质均匀, 没有分层这样的概念. 使得以往许多用二维水动力模型 ${ }^{[15-17]}$ 模拟浅水湖泊湖流 及其它水质要素迁移扩散的方法需要重新认识.

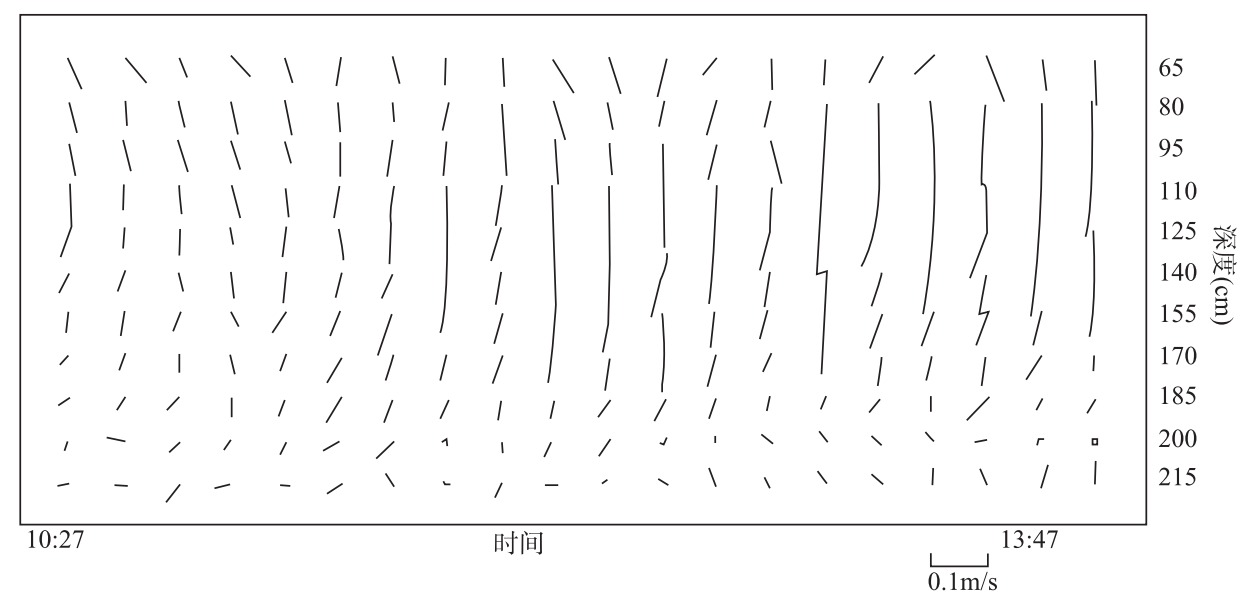

图 12003 年 7 月 14 日 10:27-13:47 太湖梅梁湾口外湖流随深度的变化(深度包括 $65,80,95,110,125,140$, $155,170,185,200,215 \mathrm{~cm}$ ), 测定间隔是 $10 \mathrm{~min}$, 水深是 $2.4 \mathrm{~m}$; 仪器为 SonTek ADCP 测流仪

Fig.1 Lake currents observed on 10:27-13:47, July 14, 2003 at the open Meiliang Bay, Lake Taihu (depths varied between $65-215 \mathrm{~cm}$ ) with a interval of $10 \mathrm{~min}$ and depth $2.4 \mathrm{~m}$ by SonTek ADCP

而与这种湖流分层相联系的是水体中的悬浮物浓度也随着深度变化, 存在着分层的现象. 监测显示, 通过分层采样分析悬浮物浓度 $(\mathrm{SS})$ 获得的风速与悬浮物浓度随深度变化 ${ }^{[18]}$, 可以看出在接近湖底 $20-50 \mathrm{~cm}$ 范围内, 悬浮物浓度变化剧烈, 完全不同于表层水体中的悬浮物浓度. 这是浅水湖泊一个有别 于深水湖泊的重要特征.

为了确定太湖梅梁湾沉积物悬浮的临界剪切力, 取梅梁湾的底泥放在实验水槽中, 放进水, 摚动底 泥使之充分悬浮, 再静止数日, 形成与野外相同的沉积结构, 再迭加造波机产生的波浪, 观察波浪从弱 到强过程中沉积物的悬浮过程 ${ }^{[19]}$. 最后经过公式计算确定梅梁湾沉积物悬浮的临界剪切力是 $0.038 \mathrm{~N} / \mathrm{m}^{2[13]}$. 对比野外观测的风浪导致底泥悬浮的过程, 此临界剪切力大致相当于野外风速 $5 \mathrm{~m} / \mathrm{s}$ 左右.

通过多次波浪观测，发现太湖大多数波浪过程的最大波高 $\left(H_{\max }\right)$ 和 $1 / 3$ 波高 $\left(H_{1 / 3}\right)$ 统计值均很小，其中 $80 \%$ 累计频率, $H_{1 / 3}$ 波高不超过 $8 \mathrm{~cm}, 98 \%$ 累积频率, $H_{1 / 3}$ 不大于 $20 \mathrm{~cm}$. 只有约 $5 \%$ 的波浪过程，其最大波高 大于 $40 \mathrm{~cm}^{[20]}$. 依据观测资料得到的波高 $\left(H_{1 / 3}\right)$ ，风速 $(W)$ 和持续时间 $(T)$ 之间的经验关系 ${ }^{[21]}$. 利用 2001 年 9 月定点观测资料，揭示了太湖 $1 / 10$ 频率大波波高、 $1 / 3$ 大波波高及平均波高与风速相关系数均大于 0.85 , 
说明风速大小是波高大小的主要控制因子 ${ }^{[22]}$.

长期以来, 有关太湖表层湖流的主要特征一直不是很清楚. 困难在于无法在同一时间获得覆盖全湖 的湖流流向和流速. 但是, 利用装备先进的多普勒测流仪, 可以获得短时间内局部水域的湖流特征. 通 过对梅梁湾表层湖流的调查, 发现无论冬夏季节, 梅梁湾都存在一个顺时针的环流 ${ }^{[23-24]}$, 在湾的东北部, 存在一个逆时针的环流. 正是这个环流的存在, 使得梅梁湾中心偏东沿岸, 常常是蓝藻水华堆积严重的 水域 ${ }^{[23]}$ ，而这也是对这个区域水质影响最大的一个因素 ${ }^{[25]}$.

获得面上湖流分布特征的另外一个有效途径就是模型的数值试验. 通过三维水动力模型的构建, 获 得了太湖地区冬、夏二季盛行风条件下太湖流场的特征 ${ }^{[26-30]}$. 东南风是太湖地区夏季的盛行风向. 在 $8.0 \mathrm{~m} / \mathrm{s}$ 东南风持续作用下, 在稳定状态下, 太湖整层平均湖流存在两大环流系统: 占据太湖西南部的顺 时针环流, 所占面积接近整个太湖的 $1 / 5$; 围绕洞庭西山逆时针环流, 占居太湖约 $1 / 2$ 水面. 环流沿岸带流 速较大, 可达 6-7 cm/s. 此外在梅梁湾的北部和贡湖湾顶还各存在一规模较小的逆时针环流,与观测结果一 致 ${ }^{[27,30]}$. 利用水动力模型进行了马山围旺对北太湖梅梁湾换水的影响. 模拟结果显示, 流场结构及环流分 布位置与围唇前相同，说明并未对梅梁湖湾及竺山湖湾口区域流场造成太大的影响 ${ }^{[28]}$. 此外，还进行了“引 江济太”对太湖水环境的影响模拟研究. 结果显示实况调水与不调水方案相比较, 贡湖湾只有叶绿素 a 浓度 改善范围超过 $50 \%$, 其他所有水质指标都谈不上显著改善; 在梅梁湾, 只有叶绿素和总氮改善的范围超过 $50 \%$, 其他指标也不明显. 就全湖而言, 也只有叶绿素有所改善, 其他水质指标改善并不显著 ${ }^{[31]}$. 利用水动 力模型, 进行风浪对蓝藻水华漂浮、堆积的影响. 模拟结果显示, 当风速达 $3 \mathrm{~m} / \mathrm{s}$ 以上时，由于水下混合作 用, 水华很难漂浮堆积 ${ }^{[32-33]}$.

浅水湖泊水动力扰动的一个直接效应就是改变水柱中及水土界面上的氧化还原环境. 根据太湖站边 上高密度连续观察结果发现, 只要有数小时的风平浪静, 就会在水柱中形成厌氧环境(Hypoxia), 即溶解 氧浓度低于 $3 \mathrm{mg} / \mathrm{L}$ 的水环境. 一旦有风浪, 厌氧环境就会立刻转为好氧环境 ${ }^{[34]}$. 这样一种间氧环境, 会 强化太湖的硝化一反硝化过程，从而增强水体的脱氮效应，这在实验中也已经证实 ${ }^{[35]}$.

浅水湖泊水动力扰动引起悬浮物浓度显著提高造成了水体光谱紫、蓝光衰减最强烈, 红光其次, 黄、 绿光衰减最弱, 随深度增加光谱中黄、绿光的比例明显上升 ${ }^{[36-37]}$. 这有利于蓝藻充分利用光谱中桔红光 进行光合作用, 这可能是蓝藻在浅水湖泊中光竞争优势的原因之一. 调查还发现太湖中各种物质对光吸 收和衰减的总贡献率中, 贡献最大的都是悬浮颗粒物, 尤其是风浪作用引起的非色素颗粒物增加 ${ }^{[38]}$. 导 致水体透明度、漫射衰减系数、真光层深度变化的主要因子是无机颗粒物而非浮游植物等有机颗粒物, 这 对于提高透明度、恢复水生植物具有非常重要的指导意义.

太湖真光层深度(能够进行光合作用的最大深度)最小的区域位于湖中心和西南水域, 平均为 $1.1 \mathrm{~m}$, 其次是梅梁湾、五里湖和贡湖湾北部, 平均为 $1.4 \mathrm{~m}$, 最大值在东太湖和胥口湾, 平均达 $2 \mathrm{~m}$. 这样的分布 格局完全与悬浮物浓度及透明度分布一致, 也与水生植物分布相一致. 说明太湖水生植物分布主要受真 光层深度的控制, 而真光层深度分布主要受悬浮物浓度控制, 即主要受水动力的控制 ${ }^{[38]}$. 最后, 利用悬 浮物浓度、太湖辐射等参数, 获得了太湖梅梁湾初级生产力的计算公式 ${ }^{[39]}$. 通过公式计算得到了梅梁湾 1995-2003 年间生产力变化, 发现 43\%的生产力来自夏季 3 个月的贡献, 而最高值出现在 1996 和 1997 年, 最低值出现在 2001 和 2003 年. 这与野外观测到的叶绿素浓度变化相一致 ${ }^{[39]}$.

上述有关浅水湖泊水动力及其生态环境效应的研究才刚刚起步. 许多工作刚刚开始. 但是随着工作 的深人, 越来越多的迹象表明, 水动力过程与太湖的许多生命过程联系密切, 包括蓝藻水华爆发的机制. 相信这个领域将逐步推动太湖生态环境机理等方面研究的深人.

\section{2 太湖沉积物与湖泊内源污染负荷}

有关太湖沉积物的研究源自对内源污染的争论 ${ }^{[40]}$. 国际上, 有关湖泊内源污染问题, 都是在深水湖 泊中获得的 ${ }^{[41-42]}$. 这样的湖泊, 一个显著的特点是没有水动力扰动的问题, 使得问题就变得较简单. 从 这样的湖泊中获得的内源污染的结论显然不适用于太湖. 太湖的内源污染究竟有多严重?

调查发现, 太湖沉积物覆盖范围约占太湖水域面积的 $48 \%$, 蓄积量约 $10 \times 10^{8} \mathrm{~m}^{3[43]}$. 发现在太湖沉积 
物中主要的磷形态为有机态磷, 活性磷占 $10 \%-30 \%$ 不等 ${ }^{[4-45]}$. 在污染严重的北部水域高于其他水域. 太 湖表层底泥生物可利用磷 (AAP) 含量范围为 7-363 $\mathrm{mg} / \mathrm{kg}$, 平均值为 $42 \mathrm{mg} / \mathrm{kg}$. AAP 含量的极值出现在梅梁 湾北部, 其余大部分区域的 AAP 含量都低于 $80 \mathrm{mg} / \mathrm{kg}$. 小梅口及大浦口这两个太湖最大的人湖河流人口 处, 表层沉积物的 AAP 含量却未出现显著升高的现象 ${ }^{[44-45]}$. 这说明, 梅梁湾和竺山湾由于其人流主要来 自无锡市和常州市，承纳了大量的城市污水，底泥中的污染物蓄积量显著高于芳溪和宜溧河这两个太湖 最大的人湖河口处.

研究发现, 太湖沉积物表层 5-10cm 的范围内, 各项物理化学指标都明显区别于其他下伏的沉积物 的指标, 说明在太湖这样的浅水湖泊中, 表层 5-10 $\mathrm{cm}$ 是不断参与上覆水交换的活动层, 当风速大于 $5 \mathrm{~m} / \mathrm{s}$ 时，沉积物就会大量悬浮. 导致大量的营养物质被释放进人上覆水中. 分析还发现，沉积物孔隙水中的 营养盐浓度远高于上覆水中营养盐浓度 ${ }^{[13]}$. 但是, 并非所有的营养盐随着沉积物的悬浮都会释放出来并 为生物所利用. 根据野外调查的结果, 在太湖梅梁湾, 随着风速的增加, 水柱中的悬浮物浓度、总氮、总 磷都随之增加而增加, 但是如溶解性的氮磷和 COD 浓度却不完全, 随风速增加而增加, 有的甚至随风速 增加, 反而下降 ${ }^{[46]}$. 在实验室进行的沉积物悬浮试验也完全证实了上述现象 (图 2$)^{[19]}$. 即在悬浮开始发生 时, 水柱中的悬浮物浓度、总氮、总磷浓度都会增加, 溶解性的生物活性磷也会少量增加, 但是随着悬浮强 度的加大, 以及时间的延长, 溶解性营养盐不再随悬浮增加而增加. 之所以出现这样的现象, 原因是如果沉 积物中富含铁、锰等金属元素，在悬浮过程中得以氧化，从而强化了其吸附溶解性磷的作用，使得水柱中的 溶解性活性磷反而会减少 ${ }^{[19]}$.
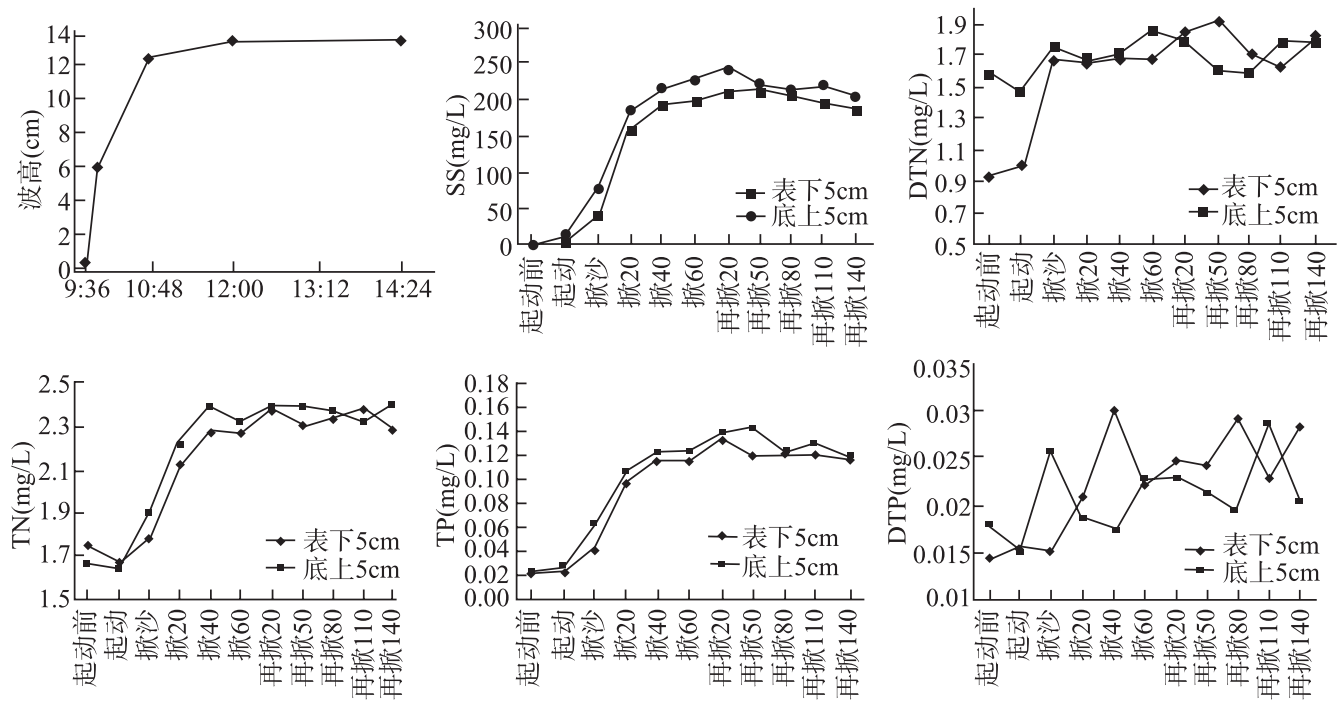

图 2 水槽试验波浪、沉积物悬浮与上覆水中营养盐浓度的变化

(其中波浪强度用波高来表示, 悬浮物浓度 (SS)、溶解性氮(DTN)、溶解性磷(DTP)、

总氮(TN)和总磷(TP)分别有表层和底层 2 个采样位置浓度表示 ${ }^{[19]}$ )

Fig.2 Wave height and contents of SS, DTN, DTP, TN, TP in overlying water in the wave flume experiments ${ }^{[19]}$

根据上述研究, 提出了有关浅水湖泊内源释放的概念性模式, 即在风浪较小的情况下, 沉积物悬浮的 数量很小, 释放数量主要靠沉积物与上覆水的浓度差, 通过分子扩散而实现, 当扰动很强时, 沉积物发生大 量悬浮, 大量的营养盐释放进人上覆水中, 增加水柱中总氮、总磷的浓度, 溶解性的氮磷释放开始也有增加, 其后取决于沉积物中铁、锰等金属含量及动力扰动的复氧强度 ${ }^{[13,46-47]}$. 一般情况下, 如果动力扰动与复氧都 很强烈的情况下，虽然水柱中总氮、总磷增加很大，但是对富营养化有贡献的溶解性氮磷增加不会很大，而 风浪过后, 许多营养盐会随着悬浮颗粒的沉降而沉人水底. 实际上, 像太湖这样的浅水湖泊, 水柱中的总磷 
浓度, 并不能很好地代表水体富营养化的情况 ${ }^{[48]}$. 在没有动力扰动的情况下, 沉积物中营养盐将按照浓度 差的分子扩散而释放，成为静态释放. 由于静态释放主要是氨氮和无机磷，因此，对水体富营养化有直 接影响, 特别是当沉积物中有机物含量很高, 在厌氧环境下降解矿化, 可以源源不断地提供给内源释放. 沉积物中的有机污染物, 归根结底是陆地上的工农业废水和城市生活污水排人的结果. 因此, 大型浅水 湖泊底泥内源污染控制的判断标准, 即首先需要控制的是那些有机质含量丰富(污染严重)而动力扰动较 弱的水域, 其次是有机质含量高而动力扰动强的水域, 对于有机质含量低而扰动很强的水域则不需要考 虑控制。

目前普遍采用底泥疏浚的方法来控制内源污染. 研究发现, 这样的方法虽然短期内(约半年时间)可 以显著降低底泥的内源释放, 但是, 随着时间的延长, 底泥上会出现新生的污染底泥, 或称“活化”, [49]. 这 些新“活化”的污染底泥, 实际上是外源污染没有切断的情况下, 外源污染输人后沉积在底部形成的. 丹 麦对 Sobygaad 湖的研究发现, 在外源输人没有控制的情况下, 水土界面的营养盐的化学平衡是向下的. 此时, 内源释放受到遏制，沉积物成了外源污染输人后的蓄积库; 而在外源污染控制后, 其营养盐的化 学平衡向上, 此时, 内源释放开始显现 ${ }^{[50]}$. 可以预见, 越是污染重的水域, 如果外源污染不切断, 疏浚后 的沉积物“活化”得越快. 从这个意义上讲, 控制内源污染, 首先必须先控制外源, 其次, 才能实施内源污 染控制.

关于太湖底泥内源释放的数量, 目前仍然有争议. 根据实验室试验结果, 在静态条件下, 太湖全湖 一年的 $\mathrm{NH}_{4}{ }^{+}-\mathrm{N}$ 释放量达 $10000 \mathrm{t}$ 左右, $\mathrm{PO}_{4}{ }^{3-}-\mathrm{P}$ 释放量达 $900 \mathrm{~kg}$ 左右 ${ }^{[46]}$. 在动态释放条件下, 一次大的动力 扰动导致的释放, 虽然有一些估算, 但是仍然有争议. 可以肯定的是, 其释放的数量级可以和外源年输 人量相当 ${ }^{[46]}$.

虽然太湖的“大”和“浅”的特征, 使得风浪导致的复氧有利于去除水柱中的一部分营养盐; 但是, 水 浅, 也意味着单位面积的沉积物上水体体积小, 环境容量低. 使得这样的湖泊, 很容易富营养化. 这样的 水体，在夏季高温下，水土界面的温度常常也会较高，微生物活跃，使得没有风浪情况下，很容易出现厌 氧环境而有机物降解速率加快, 内源污染加重. 因此, 不管有无风浪的影响, 沉积物中营养盐的释放都 会加重水体的负荷, 这也可以解释为什么这样的湖泊一旦富营养化后, 治理起来非常困难.

像太湖这样治理困难的富营养化湖泊不止一个. 在长江中下游地区，有许多浅水的富营养化湖 泊 ${ }^{[4,51]}$. 这些湖泊之所以营养水平较高, 除了水浅这个特性外, 还与其地处低洼的盆地或河流尾端, 营 养背景较高有关 ${ }^{[52]}$. 利用沉积物中硅藻化石所代表的种群组合重建的太湖历史时期的营养水平显示, 太 湖在 $1980 \mathrm{~s}$ 年代以前, 水体的总磷浓度就达到了 $60 \mu \mathrm{g} / \mathrm{L}$ 左右, 处于中营养水平. 1980 年代以后, 迅速增加, 富营养化加快 ${ }^{[33]}$. 说明太湖在历史上就处于一个营养水平较高的状态. 类似的湖泊还有长江下游的龙感 湖、太白湖等 ${ }^{[54]}$. 以上所有的迹象都显示, 像太湖这样的大型浅水湖泊，很容易富营养化，而一旦富营养 化后，治理起来难度会更大.

\section{3 太湖生态系统结构和功能与蓝藻水华}

湖泊富营养化的一个直接后果是蓝藻水华暴发. 长期以来, 有关蓝藻水华暴发的机制一直不是很清 楚. 概括而言, 既有环境因子的原因, 也有蓝藻生理生态特性方面的原因. 但是, 最主要的是营养盐的富 集. 这里的环境因子包括水体的面积和体积、水的滞留时间、水体的垂直混合程度、光的衰减特性、底 泥的再悬浮作用等; 蓝藻自身的生理与生态因子, 如伪空泡、无机碳浓缩机制、固氮能力、抗拒紫外伤 害和低光胁迫的藻胆体等 ${ }^{[1,55-56]}$. 孔繁翔等 ${ }^{[57]}$ 在太湖野外长期观测的基础上, 提出了蓝藻水华形成的四 阶段假设. 该假设认为, 蓝藻的生长与水华的形成可以将其分为越冬、复苏、生长和上浮集聚形成水华 4 个彼此相对独立但是又相互连续的 4 个阶段. 不同阶段具有不同的主导生态因子. 特定湖区中蓝藻水华 是已经确立了优势的蓝藻在合适的水文气象条件下的水平漂移集聚的结果, 并非是生物量在短时间的暴 发增长. 因此只要确定影响水华蓝藻在越冬、复苏、生长和上浮漂移形成蓝藻水华等不同阶段的主导生 态因子及其阈值, 就有可能对蓝藻水华进行预测预警.

但是, 最新的研究表明, 蓝藻水华复苏主要不是发生在沉积物中, 而是在水柱中 ${ }^{[58]}$. 这也不难理解, 
因为, 太湖地处亚热带, 冬季很少出现全湖封冻的情况. 因此, 漂浮在水体中蓝藻孢子自然会比湖底的 蓝藻水华狍子更容易复苏. 至于每年春天首先出现在太湖南部的蓝藻水华，很可能是风向所致. 根据太 湖站的多年观察，春季太湖地区仍然是以偏北风为主，即使蓝藻水华在北部水域出现，也很容易随着稳 定的偏北风而吹向太湖的南部. 包括 2007 年 5 月底的蓝藻危机事件，也与当时盛行风有关 ${ }^{[59]}$. 而最近完 成的营养盐添加对浮游植物生物量影响实验显示, 用太湖梅梁湾水分别添加氮 $(\mathrm{N})$ 、磷 $(\mathrm{P})$ 和氮磷 $(\mathrm{N}+\mathrm{P})$, 结果显示, 在梅梁湾春季 $\mathrm{P}$ 是限制因子, 氮是充分的; 而夏季、秋季却是 $\mathrm{N}$ 为主要的限制因子 ${ }^{[00]}$. 其原因 是春季由于春耕而大量使用化肥的结果 ${ }^{[61-63]}$. 进一步实验发现, 导致生物量增长的氮的上限是 $1.5 \mathrm{mg} / \mathrm{L}$ (当 $\mathrm{P}$ 供应充分的情况下), 而磷的上限是 $0.2 \mathrm{mg} / \mathrm{L}^{[60]}$ (当氮供应充分的情况下). 如果拿这两个阈值 与太湖各个水域氮磷浓度相比 ${ }^{[62]}$, 大约只有竺山湾和梅梁湾在夏季的部分时间内能够满足这样的浓度阈 值, 这与我们对这 2 个湖湾蓝藻水华严重的经验感觉相一致. 而其他水域及湖中心水域只有少数时间段 能够满足这样的浓度阈值.这也可以理解, 为什么蓝藻水华有时出现, 有时不出现. 至于为什么蓝藻水华 会成团，原因仍然不清楚. 既有可能是浮游动物捕食的结果 ${ }^{[64-65]}$. 而导致蓝藻水华上浮的机制, 有可能 是 $\mathrm{CO}_{2}$ 利用机制 ${ }^{[6]}$, 也可能是伪空泡导致的上浮机制 ${ }^{[67]}$. 至于水华上浮后的漂浮堆积, 则纯粹是一个风、 流作用下的物理过程，这也是目前预测预警蓝藻水华成灾的主要理论依据.

水体富营养化除了会导致蓝藻水华泛滥外，还会导致沉水植物的消亡. 这在国外有广泛的报道 ${ }^{[68-72]}$. 但是，是什么原因导致水生植物消亡，一直不是很清楚. 而且，由于有水生植物存在的水域常常水质清 澈, 因此, 恢复水生植物来改善水质一度被认为是湖泊富营养化治理的有效途径而被广泛使用 ${ }^{[73-75]}$. 虽 然在局部水域通过环境改善的方法, 达到了水生植物恢复的目的, 但是, 全湖性的生态修复鲜有成功的 例子 ${ }^{[73-78]}$. 我们通过太湖富营养化水平不同的两个水域(贡湖湾和梅梁湾), 水生植物生长和水生植物上 附着生物的变化与营养盐水平的关系研究, 发现富营养化程度越高, 附着生物的生物量越高. 而对水生 植物而言, 富营养化程度越高, 对其光合作用的遏制越严重, 去除附着物的水生植物的光合作用较没有 去除的水生植物的光合作用高达 $60 \%-90 \%{ }^{[79]}$.

进一步, 我们推断, 水生植物恢复需要以降低营养盐浓度为前提. 在此基础上, 我们提出湖泊治理 应该先控源截污, 其次才是生态恢复. 提出了环境条件决定生态系统类型, 而水生植物净化水质作用实 际上是生态系统反馈于环境条件, 这种反馈作用是有限的, 无法从根本上改变环境条件, 因此不宜过分 夸大. 提出 “十·五”期间在全国范围内普遍开展的水生植物(特别是沉水植物)恢复来净化水质是不切实际 的. 进一步提出湖泊生态恢复必须先诊断、后治理, 先环境改善、后恢复生态等新的观点 ${ }^{[52]}$. 这些观点的 提出, 对我国湖泊生态恢复与治理产生巨大的影响, 并在“十一五”的太湖治理规划和国家水体污染控制 与治理科技重大专项中有关湖泊治理的计划中得到了体现.

水体富营养化也会对微生物种群组成和营养盐循环产生影响. 野外调查发现在太湖沉积物中的微生 物生物量在河口区要高于开阔湖区, 在北部要大于南部, 这与污染程度成正比(图 8), 同时异养细菌的生 产力也呈现与富营养化成正比的趋势, 即梁溪河口较梅梁湾中心高, 而梅梁湾中心较太湖中心水域高 ${ }^{[00]}$. 对原生动物生物量的调查, 同样地在污染重的梅梁湾高于污染轻的湖中心水域 ${ }^{[81]}$. 与微生物和原生生物 分布态势相联系的是, 在污染严重的梁溪河口, 其水体中有机物的分解速率较梅梁湾高一倍, 较太湖中 心水域高 3 倍左右 ${ }^{[80,82-83]}$. 这与氮同位素示踪发现的在梅梁湾河口水域, 氮循环速率较梅梁湾中心和大 太湖水域高相一致(图 9), 说明, 在污染越严重的水域, 其营养物质循环速率越快, 营养盐的供应越是充 分, 因此, 营养物质的降解、矿化及其转化也快 ${ }^{[35]}$. 例如, 研究发现随着水体中磷酸盐浓度的增加(即污染 程度的加重), 磷的循环周期也从 $276 \mathrm{~min}$ 缩短到 $20 \mathrm{~min}$. 这些都表明, 越是污染严重的湖泊水体, 其营养 盐含量越丰富, 微生物的生物量及生产力也高, 营养盐循环的速率也快 ${ }^{[82-83]}$. 加重湖泊富营养化的态势, 形成一种营养盐供给的恶性循环. 富营养化还会进一步导致生态系统的多样性下降, 在水生植物多样性 和微生物的多样性方面都有发现 ${ }^{[84-85]}$, 说明富营养化还会导致生态系统稳定性下降.

上述工作的意义在于把生物的演变, 包括蓝藻水华爆发、微生物和微食物网的变化, 与决定其变化 的环境条件联系起来加以观察, 改变以往单纯以生物为主的研究方法, 真正实现了从生物学研究跨人生 态学研究的变化. 通过上述研究结果, 不难看出, 单纯通过生态恢复来净化水质是不太容易实现的. 原 
因是生态系统虽然可以反馈于环境条件, 譬如净化水质, 但是, 这种改变无法从根本上改变环境条件. 相反, 生态系统的演替, 却是由于环境条件的变化, 如污染或富营养化, 才导致了生态系统的变化. 因此, 从实现生态系统的演替(或恢复), 首先需要从改变环境着手, 即控制污染源的排放, 减轻水体的污染负荷. 只有在环境条件发生变化的情况, 恢复生态系统才有可能获得成功. 这种认识上的进步, 对于我国湖泊 治理和生态恢复无疑将产生深远的影响.

\section{4 展望}

太湖生态环境的研究热点当前仍然主要在水动力及其生态环境效应, 沉积物与内源污染机制及蓝藻 水华爆发与生态系统演替等几个方面. 之所以在这几个方面比较“热”，也是与太湖的“大”和“浅”相联系 的. 这样的地理特征, 使得水动力有着非常重要的作用. 而把水动力(湖流、波浪、光照和温度等)与生态 系统联系起来, 关键是需要找到联系的桥梁. 过去几年通过沉积物悬浮过程的研究, 初步建立了水动力 与水环境的关系(沉积物悬浮对内源释放的影响, 对光照透明度的影响), 但是与生态系统的联系尚有距 离. 而这方面, 难点是需要寻找建立双方联系的方法. 例如, 水动力会通过水体复氧, 影响水土界面上的 氧化还原电位, 进一步影响微生物的组成和优势种, 再进一步影响有机物的降解、矿化的最终产物, 但是 这些过程是如何发生的, 用什么方法能够观察到发生的过程. 这方面需要环境学家和湖沼学家(水生生物 学家)的合作努力. 实际上, 这个问题进一步也影响到对浅水湖泊营养盐的循环和转化过程，即内源释放 营养盐的来龙去脉的研究. 而营养盐的来源与供给, 是蓝藻水华爆发的一个关键过程, 至今我们对此知 之甚少. 对这方面的研究的深人将有助于揭示蓝藻水华爆发的机制.

从宏观上讲, 蓝藻水华爆发是环境条件发生变化导致的生态系统异常响应的结果. 以往的研究过于 侧重生物学和生理学上的研究, 忽略环境条件对蓝藻水华爆发的影响, 是这个工作研究难以取得突破的 原因之一. 已有的研究已经大致给我们描绘出浅水湖泊富营养化后, 生态系统的响应情况. 即富营养化 的发展, 会导致水体中浮游植物、附着生物逐步增加, 并且最终以浮游植物为优势的藻型生态系统将取 代以沉水植物为优势的草型生态系统. 同时, 营养盐的增加, 还会导致微生物生物量增加, 营养盐循环 速率加快, 加重水体的富营养化. 总体上, 富营养化会使生物趋于小型化和更短生命周期的生物占优势, 生物的多样性还会下降. 这种认识上的进步, 使得我们更容易理解, 生态恢复为什么首先需要进行环境 条件的改善, 特别是要采取措施进行控源截污, 降低营养盐负荷. 随着对生态系统中环境条件研究的加 强，相信蓝藻水华的爆发机理也将会取得实质性的进展.

\section{5 参考文献}

[1] 秦伯强. 太湖水环境面临的问题、研究动态和初步成果. 湖泊科学, 1998, 10(4): 1-9.

[2] 秦伯强, 王小冬, 汤祥明等. 太湖富营养化与蓝藻水华引起的饮用水危机一一原因与对策. 地球科学进展, 2007, 22(9): 896-906.

[3] Guo L. Doing battle with the green monster of Lake Taihu. Science, 2007, 317: 1166

[4] 国家环境保护总局. “三河”“三湖”水污染防治计划及规划. 北京: 中国环境科学出版社, 2000: 105-139.

[5] 贺 军. 科学治理: 太湖将重放异彩. 中国水利, 2006, (17): C1-C6.

[6] 吴庆龙. 东太湖养殖渔业可持续发展的思考. 湖泊科学, 2001, 13(4): 331-336.

[7] Kalff J. Limnology. Prentice Hall (2nd edition), 2003.

[8] Wetzel RG. Limnology: Lakes and rivers ecosystems. CA: Academic Press, 2001.

[9] 秦伯强, 谢 平. 长江中下游地区湖泊内源营养负荷、循环与富营养化. 中国科学(D辑), 2005, 35(增刊): 1-202.

[10] Qin BQ, Xie P. nutrient cycling, loading and eutrophication in lakes from middle and lower reaches of Yangtze River. Sciences in China (Series D), 2006, 49(Suppl. I): 1-202.

[11] Qin BQ, Liu ZW, Havens K. Eutrophication of shallow lakes with special reference to Lake Taihu, China. Hydrobiologia, 2007, 581: 1-311.

[12] Brandt SB. A bold step forward: ecosystem forecasting, integrated observing systems, and international field years for the Great 
Lakes. Journal of Great Lakes Research, 2003, 29(3): 373-374.

[13] 秦伯强, 胡维平, 高 光等. 太湖沉积物悬浮的动力机制及内源释放的概念性模式. 科学通报, 2003, 48(17): 1822-1831.

[14] 罗潋苟, 秦伯强, 胡维平等. 不同水动力扰动下太湖沉积物的悬浮特征. 湖泊科学, 2004, 16(3): 273-275.

[15] 吴 坚, 兴培民. 用非规则有限差分模式模拟太湖风成流. 中国科学院南京地理与湖泊研究所集刊, 第6集, 1989: 1-13.

[16] 马生伟, 蔡启铭. 太湖风生流及其对总磷分布影响的数值研究. 见: 蔡启铭主编. 太湖环境生态研究. 北京: 气象出版社, 1998: 30-41.

[17] 王谦谦, 姜加虎, 誉培民. 太湖和大浦河口风成流、风涌水的数值模拟及单站验证. 湖泊科学, 1992, 4(4): 1-7.

[18] 胡春华, 胡维平, 张发兵等. 太湖沉积物再悬浮观察. 科学通报, 2005, 50(22): 2541-2545.

[19] 朱广伟, 秦伯强, 张 路. 太湖底泥悬浮中营养盐释放的波浪水槽试验研究. 湖泊科学, 2005, 17(1): 61-68.

[20] 孙顺才, 黄渏平. 太湖. 北京: 海洋出版社, 2003: 310 .

[21] 胡维平, 胡春华, 张发兵等. 太湖北部风浪波高计算模式观察分析. 湖泊科学, 2005, 17(1): 41-46.

[22] 罗潋苾, 秦伯强, 胡维平等. 太湖波动特征分析. 水动力学研究与进展(A辑), 2004, 19(5): 664-670.

[23] 秦伯强, 胡维平, 陈伟民等. 太湖梅梁湾水动力及相关过程的研究. 湖泊科学, 2000, 12(4): 327-334.

[24] 罗潋苟, 秦伯强, 朱广伟等. 太湖梅梁湾冬季湖流特征. 湖泊科学, 2004, 16(1): 73-76.

[25] 秦伯强, 刘正文, 胡维平等. 太湖水源地水质净化的生态工程试验研究. 环境科学学报, 2007, 27(1): 5-12.

[26] 胡维平, 秦伯强, 菐培民. 太湖水动力学三维数值试验研究:1.风生流和风涌增减水的三维数值模拟. 湖泊科学, 1998 , 10(4): 17-25.

[27] 胡维平, 秦伯强, 兴培民. 太湖水动力三维数值试验研究: 2. 典型风场风生流的数值计算. 湖泊科学, 1998, 10(4): 26-34.

[28] 胡维平, 秦伯强, 兴培民. 太湖水动力三维数值试验研究: 3.马山围脣对太湖风生流的影响. 湖泊科学, 2000, 12(4): 335-342.

[29] 胡维平, 秦伯强, 兴培民. 太湖水动力三维数值试验研究: 4. 保守物质输移扩散. 湖泊科学, 2002, 14(4): 310-316.

[30] Luo LC, Qin BQ. Numerical simulation based on a three-dimensional shallow-water hydrodynamic model - Current circulations in Lake Taihu with prevailing wind-forcing. Journal of Hydrodynamics(Ser. B), 2004, 16(3): 341-349.

[31] Hu WP, Zhai SJ, Zhu Z et al. Impacts of the Yangtze River water transfer on the restoration of Lake Taihu. Ecological Engineering, 2008, 34(1): 30-39.

[32] 朱永春, 蔡启铭. 太湖梅梁湾三维藻类迁移模型研究. 见: 蔡启铭主编. 太湖环境生态研究. 北京: 气象出版社, 1998: 169-177.

[33] Cao HS, Kong FX, Luo Lc et al. Effects of wind-induced waves on vertical photoplankton distribution and surface blooms of Microcystis aeruginosa in Lake Taihu. Journal of Freshwater Ecology, 2006, 21(2): 231-238

[34] Zhu GW, Wang F, Zhang Y et al. Hypoxia and its environmental influences in large, shallow, and eutrophic Lake Taihu, China. Verh Internat Verein Limnol, 2008, 30(3): 361-365

[35] McCarthy MJ, Lavrentyev PJ, Yang LY et al. Nitrogen dynamics and microbial food web structure during a summer cyanobacterial bloom in a subtropical, shallow, well-mixed, eutrophic lake (Lake Taihu, China). Hydrobiologia, 2007, 581: 195-207.

[36] 张运林, 秦伯强, 陈伟民等. 太湖梅梁湾沿岸带水体生物光学特性研究. 生态学报, 2005, 25(3): 454-460.

[37] 张运林, 秦伯强, 马荣华等. 太湖典型草、藻型湖区紫外辐射的光谱衰减及影响因素分析. 生态学报, 2005, 25(9): 2354-2361.

[38] 张运林, 秦伯强, 杨龙元. 太湖梅梁湾悬浮颗粒物和CDOM的吸收特性. 生态学报, 2006, 26(12): 3969-3979.

[39] Zhang YL, Qin BQ, Liu ML. Temporal-spatial variations of chlorophylla and primary production in Meiliang Bay, Lake Taihu, China from 1995 to 2003. J Plankton Res, 2007, 29: 709-719.

[40] 兴培民, 王国祥, 胡春华等. 底泥疏浚能控制湖泊富营养化吗? 湖泊科学, 2000, 12(3): 269-279.

[41] Mortimer CH. The exchange of dissolved substances between mud and water in lakes. International Journal of Ecology, 1941, 29: 280-329.

[42] Mortimer CH. Chemical exchanges between sediments and water in the Great Lakes - Speculations on probable regulatory 
mechanisms. Limnology and Oceanography, 1971, 16(2): 387-404.

[43] Luo LC, Qin BQ, Zhu GW. Sediment distribution pattern mapped from the combination of objective analysis and geostatistics in the large shallow Taihu Lake, China. Journal of Environmental Sciences-China, 2004, 16(6): 908-911.

[44] 朱广伟, 秦伯强, 高 光等. 长江中下游浅水湖泊沉积物中磷的形态及其与水相磷的关系. 环境科学学报, 2004, 24(3): 381-388.

[45] 朱广伟, 秦伯强, 张 路. 长江中下游湖泊沉积物中磷的形态与藻类可利用量. 中国科学(D辑), 2005, 35(增刊II): 24-32.

[46] 秦伯强, 朱广伟, 张 路等. 大型浅水湖泊沉积物内源营养盐释放模式及其估算方法——太湖为例. 中国科学(D辑), 2005, 35(增刊II): 33-44.

[47] 张 路, 朱广伟, 罗潋苾等. 风浪作用下太湖梅梁湾水体磷负荷变化与水体氧化还原特征关系. 中国科学(D辑), 2005, 35(增刊): 138-144.

[48] Zhu GW, Wang F, Gao G at al. Variability of phosphorus concentration in large, shallow and eutrophic Lake Taihu, China. Water Environment Research, 2008, 80(9): 832-839.

[49] 范成新, 张 路, 王建军等. 湖泊底泥疏浚对内源释放影响的过程与机理. 科学通报, 2004, 49(15): 1523-1528.

[50] Sondergaard M, Jensen JP, Jeppesen E. Retention and internal loading of phosphorus in shallow, eutrophic lakes. The Scientific World, 2001, 1: 427-442.

[51] 成小英, 李世杰. 长江中下游典型湖泊富营养化演变过程及其特征分析. 科学通报, 2006, 51(7): 848-855.

[52] 秦伯强, 杨柳燕, 陈非洲等. 湖泊富营养化发生机制与控制技术及应用. 科学通报, 2006, 51(16): 1857-1866.

[53] Dong XH, Bennion H, Yang XD et al. Tracking eutrophication in Taihu Lake using the diatom record: potential and problems. Journal of Paleolimnology, 2008, 40: 413-429.

[54] 羊向东, 沈 吉, 董旭辉等. 长江中下游浅水湖泊历史时期营养态演化及其与水生生态系统的关系一一以龙感湖、太白 湖为例. 中国科学(D辑), 2005, 35(增刊 II ): 45-54.

[55] 宋立荣, 张＼cjkstart婷，郑凌凌. 水华蓝藻何以肆虐? 生命世界, 2007, (8): 36-49.

[56] 刘正文, 钟 萍, 韩博平. 铜绿微囊藻中紫外线保护物质类菌孢素氨基酸(MAAs)与水华形成机制的探讨. 湖泊科学, 2003, 15(4): 359-363.

[57] 孔繁翔, 高 光. 大型浅水湖泊的蓝藻水华形成机理研究的思考. 生态学报, 2005, 25(3): 589-595.

[58] Cao HS, Kong FX, Tan JK et al. Recruitment of total phytoplankton, chlorophytes and cyanobacteria from lake sediments recorded by photosynthetic pigments. International Review Hydrobiology, 2005, 90(4): 345-355.

[59] Qin BQ, Zhu GW, Gao G et al. A drinking water crisis in Lake Taihu, China: Linkage to climate change and lake management. Environmental Management, 2009(in press).

[60] Xu H, Paerl WH, Qin BQ. Nitrogen and phosphorus inputs control phytoplankton growth in eutrophic Lake Taihu, China. Limnology and Oceanography, 2009(submitted).

[61] 许朋柱, 秦伯强, Horst Behrendt等. 太湖上游流域农业土地的氮剩余及其对湖泊富营养化的影响. 湖泊科学, 2006, 18(4): $395-400$.

[62] 朱广伟. 太湖富营养化现状及原因分析. 湖泊科学, 2008, 20(1): 21-26.

[63] James RT, Havens K, Zhu GW et al. Comparative analysis of nutrients, chlorophyll and transparency in two large shallow lakes (Lake Taihu, P.R. China and Lake Okeechobee, USA). Hydrobiologia, 2009, 627: 211-231.

[64] Hessen DO, van Donk E. Morphological changes in Scenedesmus induced by substances released from Daphnia. Archiv für Hydrobiologie, 1993, 127: 129-140.

[65] Yang Z, Kong FX, Shi XL et al. Morphological response of Microcystis aeruginosa to grazing by different sorts of zooplankton. Hydrobiologia, 2006, 563: 225-230.

[66] Paerl H. Partitioning of CO, fixation in the colonial cyanobacterium Microcystis aeruginosa: A mechanism promoting surface scums. Appl Environ Microbial, 1983, 46: 252-259.

[67] Shapiro J. The role of carbon dioxide in the initiation and maintenance of blue-green dominance in lakes. Freshwater Biology, 1997, 37(2): 307-323. 
[68] Sand-Jensen K, Riis T, Vestergaard O et al. Macrophyte decline in Danish lakes and streams over the last 100 years. Journal of Ecology, 2000, 88: 1030-1040.

[69] Moss B. Further studies on the paleolimnology and changes in phosphorus budget of Barton Broad, Norfolk. Freshwater Biology, 1980, 10: 261-279.

[70] Blindow I. Decline of charophytes during eutrophication: comparison with angiosperms. Freshwater Biology, 1992, 28: 9-14.

[71] Best EPH, De Vries D, Reins A. The macrophytes in the Loosdrecht Lakes: A story of their decline in the course of eutrophication. Verh Internat Verein Limnol, 1984, 22: 868-875.

[72] Körner S. Loss of submerged macrophytes in shallow lakes in North-Eastern Germany. International Review of Hydrobiology, 2002, 87: 375-384

[73] 兴培民, 王国祥, 李正鬼等. 健康水生态系统的退化及其修复一一理论、技术及应用. 湖泊科学, 2001, 13(3): 193-203.

[74] 成小英, 李世杰, 兴培民. 城市富营养化湖泊生态恢复——南京莫愁湖物理生态工程试验. 湖泊科学, 2006, 18(3): 218-224.

[75] 秦伯强, 胡维平, 刘正文等. 太湖梅梁湾水源地通过生态修复净化水质的试验. 中国水利, 2006, (17): 23-29.

[76] 邱东茹, 吴振斌, 刘宝元等. 武汉东湖水生植被的恢复试验研究. 湖泊科学, 1997, 9(2): 168-174.

[77] 李文朝. 浅型富营养湖泊的生态恢复——五里湖水生植被重建试验. 湖泊科学, 1996, 8(增刊): 1-10.

[78］孙＼cjkstart刚, 盛连喜. 湖泊富营养化治理的生态工程. 应用生态学报, 2001, 12(4): 590-592.

[79] Qin BQ, Song YZ, Gao G. The role of periphytes in the shift between macrophyte and phytoplankton dominated systems in a shallow, eutrophic lake (Lake Taihu, China). Sciences in China (Series C), 2006, 49(6): 597-602.

[80] 高 光. 太湖微生态系统的结构和水华成灾关系. 见: 秦伯强, 胡维平, 陈伟民主编. 太湖水环境演化的过程与机理. 北 京: 科学出版社, 2004: 225-231.

[81] Wu QL, Chen YW, Xu KD et al. Intra-habitat heterogeneity of microbial food web structure under the regime of eutrophication and sediment resuspension in the large subtrophical shallow lake Taihu, China. Hydrobiologia, 2007, 581: 241-254.

[82] 高 光, 朱广伟, 秦伯强等. 太湖水体中碱性磷酸酶活性及磷的矿化速率. 中国科学(D辑), 2005, 35(增刊): 157-165.

[83] Gao G, Qin BQ, Sommaruga R et al. The bacterioplankton of Lake Taihu: abundance, biomass, and production. Hydrobiologia, 2007, 581:177-188.

[84] James C, Fisher J, Russell V et al. Nitrate availability and hydrophyte species richness in shallow lakes. Freshwater Biology, 2005, 50(6): 1049-1063.

[85] 冯 胜, 高 光, 朱广伟等. 基于16SrDNA-DGGE和FDC技术对富营养化湖泊不同生态修复工程区细菌群落结构的研究. 应用与环境生物学报, 2007, 13(4): 535-540. 